\title{
O GÊNERO “CONTO DE FADAS” EM UMA SEQUÊNCIA DIDÁTICA: ANÁLISE LINGUÍSTICO-PEDAGÓGICA
}

\author{
Bruno de Assis Freire de Lima*
}

\section{Resumo}

De acordo com Dolz et al. (2004), uma sequência didática deve promover a compreensão de determinado gênero textual a partir de atividades interacionistas capazes de "dissecar" o gênero, garantindo a apropriação das propriedades desse gênero e de suas práticas sociais. Pensando nisso, este trabalho analisa uma sequência didática sobre o gênero conto de fadas, fruto de uma parceria entre a Secretaria Estadual de Ensino do Paraná e a Universidade Estadual de Maringá. Partindo do princípio de que essa parceria se consolida entre entidades governamental e acadêmica, esperava-se que a sequência didática atendesse aos princípios linguístico-pedagógicos propostos por Dolz et al. (2004). Isso, porém, não foi verificado. A sequência didática analisada apenas reproduz atividades estruturalistas e subjetivistas pouco significativas para uma concepção de linguagem que se dizia e se pretendia interacionista.

Palavras-chave: Sequência didática. Gêneros textuais. Conto de fadas.

\section{INTRODUÇÁO}

Este trabalho centra-se na análise de um dispositivo de ensino de língua portuguesa, uma sequência didática (SD) sobre o gênero "conto de fadas", com base em cinco critérios: a) concepção de linguagem; b) conceito de gênero textual; c) concepção de leitura; d) prática social relacionada; e) compreensão do contexto social em que será desenvolvido o dispositivo. Antes da análise propriamente dita, é necessário justificar a escolha pela SD e o exemplo selecionado com o gênero "conto de fadas".

Dolz et al. (2004) definem SD como "um conjunto de atividades escolares organizadas, de maneira sistemática, em torno de um gênero textual oral ou escrito" (p. 97). Nesse texto, os autores apresentam o modelo de $\mathrm{SD}$, descrevendo sua estrutura e suas etapas. Os autores apontam que em muitas SD há atividades com abordagem estruturalista. Em geral, atividades com esse viés são condenadas pela linguística aplicada, haja vista um aparente consenso de que o ensino por uma abordagem estruturalista é menos (ou nada) significativo às necessidades comunicativas dos estudantes e que, por isso, devem ficar à margem das atividades escolares ${ }^{1}$. Diante disso, é importante questionar: será que abordagens estruturalistas são recorrentes em SD ou esse é um fenômeno evitável?

Buscando resposta a essa questão, foi iniciada a busca por um exemplo que correspondesse a uma SD, tal qual definem os autores. Curiosamente, muitos dispositivos de ensino recebem essa denominação, inclusive de outras disciplinas, mas não correspondem àquilo apresentado por Dolz et al. (2004). Isso denota a fragilidade

Doutorando em Estudos Linguísticos pela Universidade Federal de Minas Gerais. Professor do Instituto Federal Minas Gerais. E-mail: brunoaflima@gmail.com

Instrumento: R. Est. Pesq. Educ., Juiz de Fora, v. 19, n. 1, jan./jun. 2017 
na compreensão do conceito de SD por parte dos docentes e produtores de materiais pedagógicos. A busca por uma SD condizente com a proposta de Dolz foi feita pela internet, o que permitiu o acesso a uma quantidade considerável de textos cunhados como SD. Foram encontrados desde blogs destinados ao compartilhamento de SD, passando por sites que teorizavam sobre o assunto, até chegar em plataformas de secretarias de educação (municipais e estaduais), oferecendo SD para consulta e download.

Dessas três possíveis fontes, foram priorizadas as plataformas de secretarias de educação, sob a justificativa de que, por estarem disponíveis em sites de governo, os materiais disponibilizados ali possivelmente passaram pelo crivo de especialistas e que, por isso, atenderiam às características que se espera em uma SD. $\mathrm{O}$ exemplo selecionado trata-se de um trabalho feito em parceria entre a Secretaria de Estado de Educação do Paraná e a Universidade Estadual de Maringá ${ }^{2}$. Além da legitimidade promovida pela fonte (parceria estado e universidade), o gênero trabalhado na SD também serviu como critério de seleção. "Contos de fadas" exemplificam um gênero bastante familiar aos alunos do $6^{\mathrm{o}}$ ano do Ensino Fundamental (antiga $5^{\mathrm{a}}$ série), público a que se destina a SD selecionada. Trata-se de um dos primeiros gêneros com que se tem contato: é natural que esses textos sejam passados de pais para filhos, ainda na primeira infância (COELHO, 1991). Dessa feita, espera-se que seja um gênero caro aos alunos e já conhecido por eles, o que poderia ser um facilitador para a elaboração dos módulos de atividades apresentadas na SD.

Em linhas gerais, a análise da SD mostrou que a fonte de extração do exemplo não garante a qualidade da SD. Além disso, as expectativas causadas pelos critérios de análise não se realizaram: apesar da denominação de "Sequência Didática", o exemplo reproduz atividades não condizentes com as abordagens esperadas.
Afim de sistematizar a organização deste trabalho, o texto foi dividido em três sessões, assim especificadas: na sessão 1, são apresentadas as categorias estabelecidas para a análise da SD. $\mathrm{Na}$ sessão 2, as atividades que compóem a SD são descritas e analisadas. As consideraçóes finais estão na sessão 3 , a que se seguem as notas explicativas e as referências bibliográficas. Sugiro que, para prosseguir na leitura deste trabalho, o leitor visite a SD escolhida, o que, certamente, será preponderante para a compreensão deste texto.

\section{Categorias de análise}

Cinco categorias de análise serão consideradas no estudo sobre a SD escolhida. Essas categorias versam sobre linguagem, gênero, leitura, práticas sociais e contexto social. São categorias-chave para o sucesso pedagógico do dispositivo de ensino "sequência didática”, conforme será verificado nas subseções de 1.1. a 1.5 .

\subsection{ConcePÇão de Linguagem}

Essa talvez seja a "categoria-chave" de análise, uma vez que a concepção de linguagem interfere diretamente nas outras categorias. Segundo Geraldi (1984), são três as concepções de linguagem: a) linguagem como expressão do pensamento (desde a tradição gramatical grega até, aproximadamente, meados do século $\mathrm{XX}$, quando começam a figurar os preceitos estruturalistas propostos por Saussure - 1916); b) linguagem como instrumento de comunicação (a partir de Saussure - 1916 - até 1960, quando os estudos relacionados à reflexão sobre a relação língua e sociedade se fortalecem); c) linguagem como processo de interação (década de 1960 até os dias de hoje).

Uma concepçáo de "linguagem como reflexo do pensamento" reflete uma concepção de leitura passiva, 
não interacional. Em se tratando de $\mathrm{SD}$, a concepção de linguagem deve ser condizente com práticas educacionais que permitam que os alunos "apropriem-se das noçóes, das técnicas e dos instrumentos necessários ao desenvolvimento de suas capacidades de expressão oral e escrita em situações de comunicação diversas" (DOLZ et al., 2004, p. 96). Concepções de linguagem que não consideram a interação como meio de expressão linguística não contribuirão para o desenvolvimento das capacidades supracitadas e, por esse motivo, fragilizariam os propósitos da sequência didática. Dessa forma, a SD sobre conto de fadas será analisada à luz da concepção de linguagem como interação.

\subsection{Conceito DE GÊNero TeXtual}

Ao tratar da noção de gênero textual, Bakhtin (1992) abarca os produtos da atividade de linguagem em funcionamento permanente na sociedade, os quais apresentam características relativamente estáveis e disponíveis para os contemporâneos e para as futuras geraçôes. Para Marcuschi (2002), a funcionalidade do gênero vai além do campo linguístico por cumprir um papel social e cultural, ordenando e estabilizando as atividades comunicativas rotineiras. A escolha de um gênero em situação de comunicação não ocorre de maneira aleatória, espontânea, mas considera fatores como o objetivo do texto, o locutor, o interlocutor, o assunto etc. Já Bronckart (1999) considera os textos produtos da atividade de linguagem humana e são conceituados em função de seus objetivos.

Apoiado em Bakhtin, Bronckart define os gêneros textuais a partir das sequências "relativamente estáveis", que se moldam de acordo com a atividade linguística e discursiva em que os interlocutores estão inseridos. Desse modo, os gêneros podem ser considerados como verdadeiras ferramentas no cumprimento de determinadas funçóes na área da atividade de linguagem. No escopo deste trabalho, cabe questionar: o conceito de gênero inferido no dispositivo cumpre o papel de levar o aluno ao efetivo exercício social da linguagem? É, pois, sobre esse prisma que a análise se pautará.

\subsection{ConCEPÇấo DE LEITURA}

Para Dolz et al. (2004), para elaborar os módulos que compõem uma SD, "existe um arsenal bastante diversificado de atividades e de exercícios que relacionam intimamente leitura e escrita, oral e escrita, e que enriquecem consideravelmente o trabalho em sala de aula”. Por uma questáo de coerência interna da proposta de SD que visa ao ensino de gêneros, esperase uma concepção de leitura sociointeracionista, que considera a leitura um processo perceptivo e cognitivo que se utiliza da interação entre leitor e autor tendo como veículo o texto.

Nessa perspectiva, a leitura é vista como um processo ativo de construção de sentido, o que se fragiliza diante de atividades de cunho meramente estruturais. No processo ativo de construção de sentido, a compreensão do texto e do gênero parte não apenas da informação dada pelo autor, mas também pelo conhecimento prévio (conhecimento linguístico e extralinguístico) que cada sujeito carrega em sua formação (KLEIMAN, 2005).

\subsection{Prática social relacionada}

Nas três concepções de gênero apontadas em 1.2, os autores convergem quanto à proveniência dos gêneros: são resultado de atividades humanas. Assim, como o objetivo das SD é ensinar gêneros, pressupóe-se que alguma prática social esteja coerentemente relacionada ao gênero. A SD escolhida trata de "contos de fadas", a partir da qual questiona-se: que práticas podem estar relacionadas a esse gênero? Uma possibilidade está na 
transposição das narrativas desse gênero em outros, como HQs, texto teatral ou até mesmo gêneros menos prováveis, como propagandas e anúncios classificados. Dessa forma, espera-se que o trabalho de transposição de um gênero a outro seja proposto na SD, garantindo práticas sociais que vão além do espaço escolar.

\subsection{CoMPrEENSÁo do CONTEXTO SOCIAL EM QUE SERÁ DESENVOLVIDO O DISPOSITIVO}

A SD que será analisada foi elaborada em parceria entre a SEE/PR e a Universidade Estadual de Maringá. Essa SD foi planejada para alunos de língua portuguesa do $6^{\circ}$ ano, direcionada a alunos da rede pública estadual, geralmente marcado por um público heterogêneo, de diversas camadas sociais e com diferentes vivências de leitura e letramento. Como já citado neste trabalho, por a SD ser proveniente da parceria estado x academia, espera-se por rigor técnico, no qual se atenda plenamente às características linguístico-pedagógicas de uma SD.

\section{Descriçấo e análise da SD COM “CONTOS DE FADAS"}

Essa sessão foi dividida em duas subseçôes. $\mathrm{Na}$ primeira, foi feita a descrição da SD selecionada, ao passo que, na segunda, há a análise dessa SD. A análise não foi dividida por categoria, mas foi feita em "texto corrido", uma vez que essas categorias se interrelacionam. Essa estratégia também foi adotada para garantir a continuidade do desenvolvimento da análise.

\subsection{Descriçấo da SD “CONTOS DE FADA”}

A SD escolhida inicia-se com a identificação básica: traz o nome da professora, da disciplina, o gênero textual e a quantidade de aulas. Há uma introdução, com aspectos teóricos do próprio Dolz. O texto introdutório se inicia com esta passagem:

O trabalho com sequências didáticas permite a elaboração de contextos de produção de forma precisa, por meio de atividades e exercícios múltiplos e variados com a finalidade de oferecer aos alunos noçóes, técnicas e instrumentos que desenvolvam suas capacidades de expressão oral e escrita em diversas situações de comunicação (DOLZ, 2004. p. 9).

A partir dessa consideração, infere-se um compromisso de que a SD tenha "atividades e exercícios múltiplos e variados [...] em diversas situaçóes de comunicação". Sequencialmente, há a afirmação de que a SD é constituída por uma

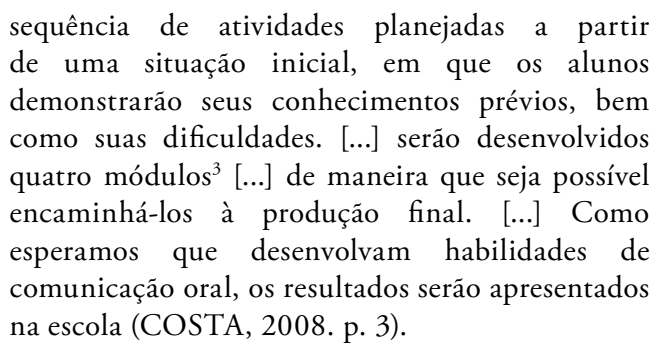

Ao que parece, a SD está em consonância com o esquema básico proposto por Dolz et al., que aponta a necessidade de uma apresentação, à qual se seguirá uma produção inicial, seguida de módulos de atividades, até uma produção final, que permitirá aferir a apropriação do gênero por parte dos alunos.

$\mathrm{Na}$ sequência da $\mathrm{SD}$, há uma sessão intitulada "Fundamentação Teórica", que traz consideraçôes sobre o gênero conto de fadas, propondo uma comparação entre as versóes de "Cinderela" e "A Gata Borralheira", considerando seus autores e o momento de produçáo. Inicia-se, assim, a contextualização dos textos que serão os condutores das atividades da SD.

A primeira atividade prevista na SD é a apresentação da proposta. É sugerido que o professor faça perguntas genéricas sobre o gênero, do tipo: "Você sabe o que é um conto de fadas?"; "Conhece algum?”. 
O professor é orientado a tomar nota dos possíveis títulos que serão citados pelos alunos. Eventuais características dos gêneros que forem citadas também devem ser anotadas, como personagens-fantásticos, temporalidade, marcadores discursivos, dentre outras.

Terminada essa atividade, passa-se, então, ao que a SD chama de módulo de atividade. Nesse módulo, o professor deve continuar questionando a turma sobre o gênero. No entanto, esses questionamentos recaem sobre os contos "Cinderela" e "A Gata Borralheira". Perguntas como "Você conhece o conto de fadas "Cinderela/A Gata Borralheira?”; "Se sim, vocês leram, assistiram ou apenas ouviram falar sobre eles?"; "Como é, resumidamente, a história destes contos de fadas?”. É sugerido, então, que a turma faça a leitura dos dois textos.

O módulo 2 busca levantar as principais diferenças entre os dois contos. É apresentada uma tabela, que deve ser preenchida pelos alunos com as seguintes informações:

Tabela 1 - Tabela sobre contos de fadas

\begin{tabular}{|l|l|l|}
\hline \multicolumn{1}{|c|}{ ITENS } & GATA BORRALHEIRA & CINDERELA \\
\hline Autor & & \\
\hline Pai & & \\
\hline Maie & & \\
\hline Ser fantástico & & \\
\hline Amigos & & \\
\hline Inimigos & & \\
\hline Duraçăo do baile & & \\
\hline Roupagem & & \\
\hline Meio de transporté & & \\
\hline Término do encanto & & \\
\hline Localizaçăo da princesa & & \\
\hline Destecho & & \\
\hline
\end{tabular}

Fonte: Disponível em: <https:/goo.gl/RUXwLk>

De acordo com a SD, essa atividade é proposta para que os alunos percebam a possibilidade de a mesma história ser contada de "maneiras distintas". Certamente é uma atividade que tem sua importância, uma vez que requer o reconhecimento de informaçóes explícitas nos textos. No entanto, há de se ressaltar que se trata de uma atividade de cunho estrutural, que não é capaz de estabelecer com precisão "as principais diferenças entre os dois contos". Há de se considerar que as diferenças também estão em nível macroestrutural, como época em que os contos foram escritos, o contexto histórico, objetivos dos textos, e assim por diante.

Quanto aos módulos 3 e 4, ambos são destinados a trabalhos com filme. Tratam-se de duas versões de Cinderela. A SD propõe a mesma atividade do módulo 1 , ou seja, os alunos devem levantar as características arroladas no quadro. Igualmente são propostas perguntas, tais como "Você gosta do conto?"; "O final da história é legal?"; "Para você, a Cinderela conseguiu realizar seu sonho?”.

Embora os filmes sejam intertextualmente ligados ao conto da Cinderela, eles constituem novo gênero, o que não é, necessariamente, um problema, desde que sua exibição e posteriores atividades sirvam para a compreensão e apropriação do gênero conto de fadas. Perguntas vagas e de cunho subjetivo pouco agregam para o fim teoricamente proposto para as SDs.

O módulo 5 orienta o professor a realizar alguns apontamentos acerca do gênero "conto de fadas" (histórico, escritores, outros tipos de contos etc.). Deverá também instruir os alunos quanto aos elementos da narrativa: O quê? Com quem? Quando? Onde? Como? Esses elementos devem ser localizados nos textos pelos alunos.

Antes de chegar ao que a SD chama de "Produção Final”, há o módulo 6, sintetizado na leitura e discussão de outros contos de fadas. Na produção final, os alunos são convidados a recontar o final da história "Cinderela" ou "A Gata Borralheira". O resultado desses textos será apresentado para a comunidade escolar (não é explicitado como isso será feito, se os textos seráo representados, reproduzidos ou declamados) e serão disponibilizados na biblioteca da escola. 


\subsection{ANÁlise da SD}

Há diversos problemas com a SD proposta. Inicialmente, o que a SD chama de "situação inicial" não corresponde ao que Dolz chama de "produção inicial”. A situação inicial tratada na SD nada mais é do que a apresentação da proposta. Observa-se que os protagonistas de cada uma dessas etapas são diferentes: a proposta é apresentada pelo professor, mas a produção inicial é do aluno.

A SD, tal qual projetada por Dolz, parte de uma produção textual com os conhecimentos prévios que os alunos têm sobre o gênero. Isso não foi garantido na SD da SEE/PR, ou seja: os alunos não produzem nenhum texto, o que fere os princípios metodológicos do trabalho com SD.

As perguntas que são sugeridas ao longo dos módulos de atividades são perguntas retóricas, evasivas, que levam os estudantes a "achismos" e subjetividades sobre os textos. Não há nenhuma pergunta que recaia sobre aspectos interpretativos, nem mesmo no módulo 1, que deveria proporcionar a comparaçáo entre dois contos de fada.

As atividades que são propostas nos módulos de 3 a 5 são exatamente as mesmas: localizar elementos na superfície textual. Obviamente essa atividade tem sua relevância, como já dito: uma das formas de se apropriar de um gênero é perceber elementos que o constituem. No entanto, no próprio corpo de texto da $\mathrm{SD}$, é delineada a necessidade de atividades "múltiplas e variadas". A repetição da atividade de localização de informaçôes depóe contra essa característica básica da SD. O módulo 6 sugere a discussão de outros contos de fada, mas não instrumentaliza como isso será feito. Assim, os módulos de atividades, que deveriam ser variados, são repetitivos, circulares e pouco contribuem para o desenvolvimento das noçóes do gênero.

Além disso, há um predomínio por supostas atividades orais. As únicas atividades de escrita são o reconhecimento e registro de informações explícitas nos textos e a reinvenção do final de um conto. As atividades de registro - exceto a "produção final" são de natureza estruturalista que sequer contribuem para o conhecimento metalinguístico do aluno, quem dirá para o seu potencial interpretativo ou discursivo. Novamente, esse tipo de atividade tem seu valor, mas na SD em análise essa atividade se repete em quase todos os módulos, não permitindo a diversificação de atividades, conforme preveem Dolz et al. (2004).

Como se vê, o dispositivo é mais um exemplo de um conjunto de atividades que recebem o nome de SD, mas que não contempla as etapas de uma SD. Partindo do princípio de que os gêneros surgem $d a$ e na interação, é possível afirmar que o conceito de gênero presente na SD não coaduna com uma abordagem interacionista: os alunos apenas identificam informações explícitas nos textos e emitem impressóes pessoais sobre eles. Dessa maneira, as concepções de leitura e linguagem ficam igualmente fragilizadas. Os alunos não participam da construção de sentido dos textos, não são propostas perguntas nem atividades interpretativas. O que é proposto não leva à reflexão sobre os usos da linguagem, tampouco serve para aprimorar as habilidades de leitura e escrita - e posterior apropriação do gênero.

Como já dito ao longo deste trabalho, os contos de fadas constituem um interessante gênero para a faixa etária. Reduzir o trabalho com esse gênero apenas à reelaboração do final do conto não garante a apropriação do gênero. Além disso, o resultado do trabalho (produção "final") será bastante repetitivo: textos idênticos apenas com final diferente. A SD ainda peca em não explicitar como será feita a apresentação desses textos: reunir os textos e deixá-los na biblioteca da escola não garante sua circulação na comunidade escolar, quiçá fora dela, o que fere a possíveis práticas sociais que estariam relacionadas ao gênero em estudo. 


\section{CONSIDERAÇÓES FINAIS}

A SD analisada mostrou o predomínio de atividades estruturalistas, sem explorar outras abordagens que poderiam contribuir para o sucesso da SD. Ressalta-se que essas atividades estruturalistas estão "mascaradas", por meio da localização de informações explícitas no texto. Essas informações não são de cunho gramatical (o que não diminui a inadequação das atividades), mas recorrem a aspectos constitutivos do gênero em estudo. Localizar essas informações não é uma atividade condenável. Condenável é o fato de a SD trazer apenas atividades dessa natureza. Aliás, a mesma atividade, repetidamente, em mais de um módulo.

Esperava-se uma SD dentro dos moldes formais e metodológicos propostos por Dolz et al. (2004), justamente pela escolha do dispositivo ter sido feita por meio de uma plataforma governamental. Como argumentado, o dispositivo analisado nada mais passa que um conjunto de atividades que se repetem, que contribuem pouco para apreensão do gênero, mas que recebe o nome de SD. Os resultados são desanimadores: se o fruto de uma parceria entre governo (SEE/PR) e universidade (UEM) apresenta tantas fragilidades, conclui-se que devem faltar estudos sobre esse dispositivo de ensino entre os docentes e, mais que isso, devem faltar práticas sistemáticas de criação desse dispositivo.

\section{THE GENRE “FAIRY TALE” IN A DIDACTIC SEQUENCE: LINGUISTIC-PEDAGOGICAL ANALYSIS}

\section{Abstract}

According to Dolz et al. (2004), a didactic sequence should promote the comprehension of a given textual genre, based on interactionist activities capable of "dissecting" the genre, guaranteeing the appropriation of the properties of this genre and its social practices. This work analyzes a didactic sequence on the genre fairy tale, the result of a partnership between the State Department of Education of Paraná and the State University of Maringá. Based on the principle that this partnership is consolidated between governmental and academic entities, it was expected that the didactic sequence would meet the linguistic-pedagogical principles proposed by Dolz et al (2004). This, however, was not verified. The didactic sequence analyzed reproduces only structuralist and subjectivist activities that are not significant for a conception of language that was said and intended to be interactionist.

Keywords: Didactic sequence. Textual genres. Fairy tale.

\section{El GÉnero “Cuento de hadas" EN UNA SECUENCIA DIDÁCTICA: EL ANÁLISIS LINGÜÍSTICO Y PEDAGÓGICO}

\section{Resumen}

Según Dolz et al. (2004), una secuencia didáctica debe fomentar la comprensión de un género en particular, de las actividades interaccionistas capaz de "diseccionar" el género, garantizando la titularidad de las propiedades de este tipo y sus prácticas sociales. Pensando en ello, el presente trabajo analiza una secuencia didáctica sobre el género de cuento de hadas, el resultado de una colaboración entre el Departamento de Educación del Estado de Paraná y la Universidad Estatal de Maringá. Suponiendo que esta asociación se consolida entre el gobierno y las entidades académicas, se espera que la secuencia de enseñanza cumple con los principios lingüísticos 
y pedagógicos propuestos por Dolz et al (2004). Pero esto no fue verificada. La secuencia didáctica analizada sólo desempeńa actividades estructuralistas y subjetivistas menores a una concepción del lenguaje que se dice y la intención de interacción.

Palabras clave: Secuencia didáctica. Géneros. Cuento de hadas.

\section{Notas}

\begin{abstract}
Não é meu objetivo delongar essa discussão, embora eu acredite que atividades estruturalistas possam ter lugar nas aulas de língua portuguesa, como, aliás, ainda é visto em muitas práticas de ensino de língua materna. O ideal, certamente, é a busca pelo "meio-termo": as atividades estruturalistas têm seu valor, desde que devidamente contextualizada e com critérios e objetivos bemdefinidos.

2 Disponível em: <http://www.gestaoescolar.diaadia.pr.gov.br/ arquivos/File/producoes_pde/md_izolinda_jesus_duque_costa. pdf $>$. Para evitar que a leitura deste trabalho seja comprometida pela possível retirada da SD do site da SEE/PR, o arquivo da SD foi alocado em outro endereço, hospedado no DropBox, através do link: <https://goo.gl/RUXwLk>. Acesso em: 18 nov. 2015.

A autora cita 4 módulos, mas a SD apresenta 6 módulos.
\end{abstract}

\section{REFERÊNCIAS}

BAKTHIN, M. Estética da criação verbal. Tradução Maria Ermantina Galvão Pereira. 2. ed. São Paulo: Martins Fontes, 1992.

BRONCKART, J. P. Atividade de linguagem, textos e discursos: por um interacionismo sócio-discursivo; traduçáo Anna Rachel Machado, Pericles Cunha. São Paulo: EDUC, 1999.

COELHO, N. N. Literatura infantil - teoria, análise e didática. 5. ed. São Paulo: Ática, 1991.

COSTA, I. D. Sequência didática para o trabalho com o gênero textual conto de fadas. Disponível em: <https://goo.gl/ RUXwLk> Acesso em 08 out. 2016.

DOLZ, J.; NOVERRAZ, M.; SCHNEUWLY, B. Sequências didáticas para o oral e a escrita: apresentação de um procedimento. IN: DOLZ, J.; SCHNEUWLY, B. Gêneros orais e escritos na escola. Tradução e organização de Roxane Rojo e Glaís Sales Cordeiro. Campinas: Mercado de Letras, 2004.
GERALDI, J. W. (Org.). O texto na sala de aula: leitura e produção. 2. ed. Cascavel: Assoeste, 1984.

KLEIMAN, A. Texto e leitor: aspectos cognitivos da leitura. Campinas: Pontes, 2005.

MARCUSCHI, L. A. Gêneros textuais: definição e funcionalidade. In: DIONISIO, A. P. et al. (org). Gêneros textuais e ensino. Rio de Janeiro: Lucerna, 2002.

SAUSSURE, F. (1916). Curso de linguística geral. Tradução Antônio Chelini, José Paulo e Izidoro Beinkstein. São Paulo; Cultrix, 1975.

Enviado em 14 de dezembro de 2016. Aprovado em 20 de fevereiro de 2017. 